\title{
PROTÓTIPO PARA PROCESSOS DE ROTOMOLDAGEM COM INCREMENTO DE SEÇÕES DE PRÉ E PÓS-CÂMERA DE AQUECIMENTO
}

\author{
João Batista Regis Pires (IFBA) joaobatistaregispires@gmail.com \\ Márcio André Fernandes Martins (UFBA) marciomartins@ufba.br
}

\section{Resumo}

Atualmente a produção de caixa d'água de polietileno envolve um processo de transformação termoplástica, a saber rotomoldagem, na qual é utilizado o gás natural como fonte de energia Entretanto, nesse processo gera-se desperdício energético expressivo na etapa de retirada do molde da câmara de aquecimento no final de cada ciclo, exigindo incrementos substanciais de energia para partida do novo ciclo, aumentando assim o tempo de produção, e, como consequência, tais condições impõem decrementos na produtividade. Neste sentido, este artigo propõe incrementar um arranjo arquitetônico de seções de pré e pós-câmera de aquecimento em um protótipo de rotomoldagem, visando à melhoria energética e redução do tempo de produção. Os resultados mostraram uma redução do tempo de produção e consumo energético em $\mathrm{kWh} / \mathrm{h}$ de cada ciclo, mantendo as principais propriedades mecânicas da peça. A partir dos resultados experimentais obtidos do protótipo proposto, constata-se a factibilidade na redução dos custos de produção, proporcionando a um futuro investidor visualizar que para cada unidade monetária gasta em kWh de energia consumida obtém-se um percentual de redução de custo em cada ciclo produtivo.

Palavras-chaves: Processo de rotomoldagem. Eficiência energética. Engenharia de produção.

\section{Introdução}

A rotomoldagem caracteriza-se também por ser um processo de baixo custo para a obtenção de peças ocas com paredes uniformes e regiões livres de tensões. Do ponto de vista operacional, a rotomoldagem consiste de um processo composto pelas etapas de carregamento, aquecimento e rotação, resfriamento e desmoldagem, no qual o molde gira biaxialmente dentro de uma câmara de aquecimento, com temperatura e velocidades controladas (REVYAKO; KHROL, 2010; RUBIO, 2016). Essas etapas são sumarizadas como segue:

- Carregamento, na qual o molde é abastecido com polietileno de média densidade em forma de pó. A quantidade abastecida é em função da espessura que se deseja da peça, 
dura em média de 2 minutos;

- Aquecimento e rotação, na qual o controlador da fonte de energia da câmera de aquecimento é ligado. Inicia com a temperatura ambiente, no primeiro ciclo, até chegar aos $270{ }^{\circ} \mathrm{C}$, permanecendo nesta, até finalizar a rotomoldagem da peça, dura em média de 15 minutos;

- Resfriamento e rotação, na qual é desligado o aquecimento, dura em média 10 minutos nos quais o molde é girado biaxialmente e a peça é resfriada o suficiente para solidificá-la no formato do molde e, posteriormente ser desprendida;

- Desmoldagem, na qual a peça é removida do molde.

A Figura 1 sumariza o comportamento do material em função do tempo até a etapa de resfriamento, qual seja: (a) material na forma de pó; (b) material na forma de pó + fusão; (c) fusão incompleta; (d) fusão completa; (e) resfriamento da peça (PISANU, 2008).

Figura 1 - Ciclo térmico na rotomoldagem (linha laranja = temperatura do forno; linha amarela = temperatura no interior do molde)

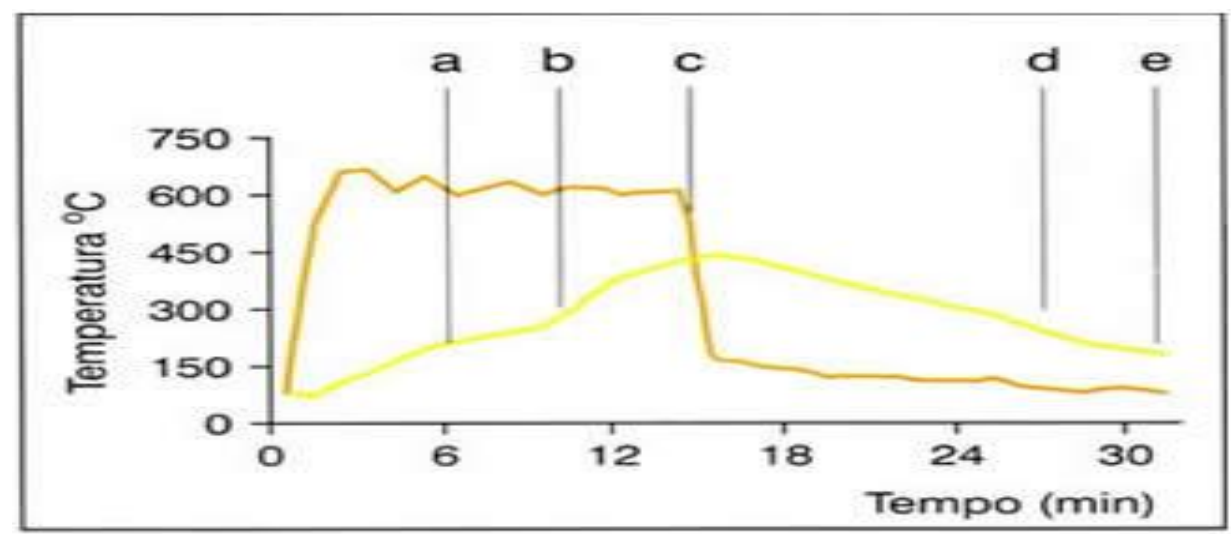

Fonte: Revista Ferramental (2007)

Em face do exposto, percebe-se que a rotomoldagem é um processo de produção constituído por um longo período de ciclo produtivo indesejado de modo que os custos com matéria prima e energia são os principais custos de produção deste processo (SLĂTINEANU et al., 2012). Uma forma de minimizar este custo seria reaproveitar a energia desperdiçada no final de cada ciclo produtivo (BARRETO, 2008).

Dentro deste contexto, o objetivo deste trabalho consiste em incrementar um arranjo arquitetônico de seções de pré e pós-câmera de aquecimento em um protótipo de rotomoldagem, visando uma análise de melhoria da eficiência energética, redução do tempo 
de produção e seus custos associados, preservando as propriedades físico-químicas do material.

Nesta primeira parte do trabalho proposto, este artigo apresenta os resultados que dizem respeito à produtividade do processo, tomando como base de estudo, o tempo e custo de produção a partir de amostras produzidas com o protótipo, operando nos modos com as seções de pré e pós-câmera de aquecimento, e comparando-os com o processo no modo de operação convencional na qual é comercializada no mercado.

\section{Materiais e métodos}

A metodologia utilizada consistiu na construção de um equipamento protótipo contendo uma câmara de aquecimento, aquecida através de banco de resistência de 4000 Watts de potência, alimentado numa tensão de $220 \mathrm{~V}$, e desenvolvimento da modelagem do tempo e do consumo energético.

O equipamento desenvolvido foi composto por um arranjo arquitetônico das seções de pré e pós-câmera de aquecimento incorporado à câmara de aquecimento, com a finalidade de armazenar a energia térmica do ciclo, permitindo reutilizá-la no ciclo seguinte. O aparato tecnológico é constituído de controladores PID, que controlam as temperaturas das câmeras de aquecimento e monitoram as temperaturas retidas nas seções de pré e pós-câmera. Além disso, o protótipo possui um sistema embarcado de controle PWM de velocidade dos servomecanismos relacionada à rotação dos moldes.

A operação do equipamento foi feita de três formas: (i) câmera de aquecimento com controlador desligado (off) - modo convencional; (ii) câmera de aquecimento com controlador desligado (off), com as seções de pré e pós-câmera de aquecimento, na qual o controlador é desligado tendendo perder energia (decaimento de temperatura) ao término de cada ciclo; e (iii) câmera de aquecimento com controlador ligado (on), com as seções de pré e pós-câmera de aquecimento, na qual o controlador permanece ligado, mantendo a temperatura de set point de $270^{\circ} \mathrm{C}$, mesmo após terminado o ciclo.

O procedimento de coleta de dados foi baseado no levantamento do consumo energético (energia elétrica gasta por hora de consumo na qual é dada em $\mathrm{kWh}$ ) para produzir cinco peças, a partir de amostras pesadas em balança de precisão, com o equipamento operando nos três modos de operação descritos anteriormente. Durante cada modo de operação, foram 
medidos o percentual de tempo em que as resistências permaneceram ligadas e o tempo total de produção, depois calculado o consumo elétrico e custos de produção.

O processo proposto é ilustrado na Figura 2, na qual além de conter quatro etapas do equipamento convencional, é acrescido de mais duas etapas que terão a função de reter o calor, que antes era perdido na câmara de aquecimento no final de cada ciclo.

Figura 2 - Fluxograma do novo processo

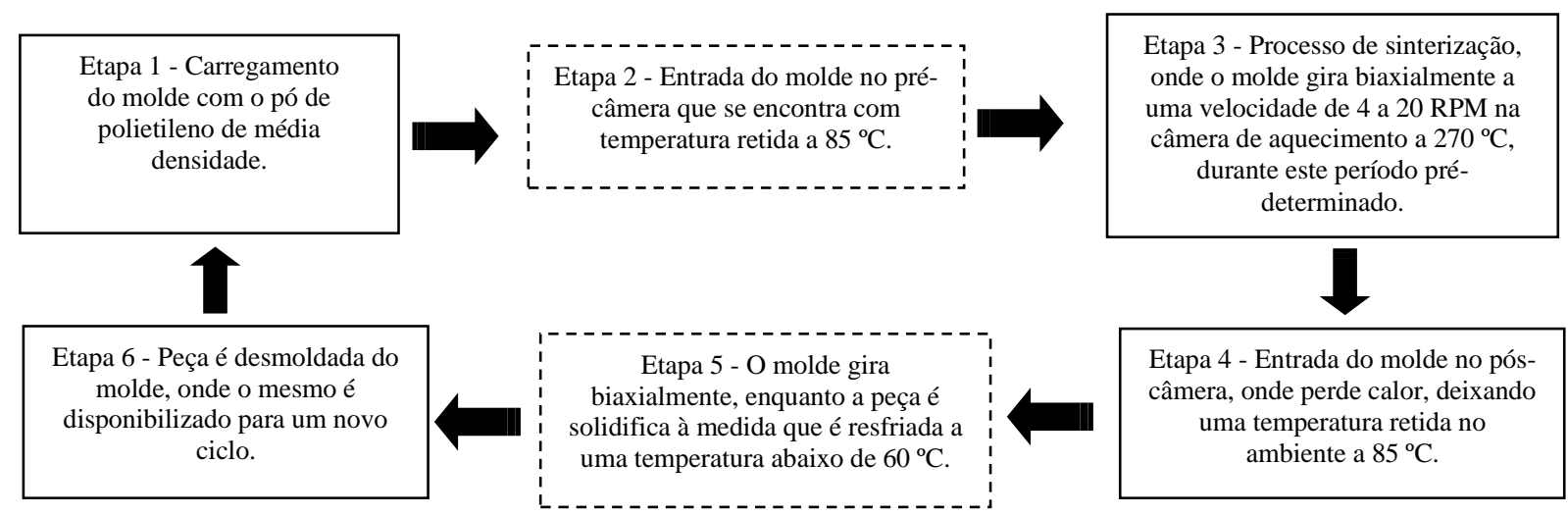

Fonte: Próprio autor (2018).

As etapas tracejadas tem a função de cobrir a lacuna que limita os processos convencionais, formados por longos períodos de aquecimento e desperdício de energia (SLĂTINEANU et al., 2012; GONZÁLEZ-NUÑES et al., 2018). Com isso, torna-se possível um processo com mais etapas pelas quais o molde percorre, proporcionando reaproveitar a temperatura acumulada na seção pré-câmera, permitindo que um novo ciclo se dê com temperatura retida em torno de $125^{\circ} \mathrm{C}$, no modo de operação com controlador desligado (off) e $200{ }^{\circ} \mathrm{C}$, para o modo de operação com controlador ligado (on), proporcionando um ganho inicial de temperatura e tempo.

\section{Resultados e discussão}

Os dados utilizados no cálculo de consumo energético da câmera de aquecimento são ilustrados nas Tabelas 1,2 e 3 .

Tabela 1 - Consumo energético da câmera de aquecimento (modo convencional): controlador desligado (off)

\begin{tabular}{lccccc}
\hline & Amostra 1 & Amostra 2 & Amostra 3 & Amostra 4 & Amostra 5 \\
\hline Tempo de ciclo (min.) & $18: 05$ & $18: 11$ & $17: 45$ & $19: 20$ & $18: 10$ \\
Potência parcial em kWh & 0,94 & 0,93 & 0,88 & 0,89 & 0,92 \\
\hline Potência total em kWh & 4,57 & & & & \\
\hline
\end{tabular}


Tabela 2 - Consumo energético com o arranjo pré /pós-câmera de aquecimento: controlador desligado (off)

\begin{tabular}{lccccc}
\hline & Amostra 1 & Amostra 2 & Amostra 3 & Amostra 4 & Amostra 5 \\
\hline Tempo de ciclo (min.) & $14: 50$ & $15: 15$ & $17: 12$ & $17: 13$ & $15: 45$ \\
Potência parcial em kWh & 0,63 & 0,63 & 0,76 & 0,87 & 0,62 \\
\hline Potência total em kWh & 3,52 & & & \\
\hline
\end{tabular}

Fonte: Próprio autor (2018).

Tabela 3 - Consumo energético com o arranjo pré /pós-câmera de aquecimento: controlador ligado (on)

\begin{tabular}{lccccc}
\hline & Amostra 1 & Amostra 2 & Amostra 3 & Amostra 4 & Amostra 5 \\
\hline Tempo de ciclo (min.) & $09: 40$ & $12: 15$ & $08: 01$ & $09: 01$ & $08: 02$ \\
Potência parcial em kWh & 0,25 & 0,39 & 0,12 & 0,22 & 0,19 \\
\hline Potência total em kWh & 1,17 & & \\
\hline
\end{tabular}

A mensuração foi realizada tomando como base o percentual de tempo em que a resistência se manteve ligada, durante o processo de produção das cinco peças. Vale salientar que o consumo máximo (energia máxima consumida em $\mathrm{kWh}$ ) pela resistência acontece quando o percentual de tempo é $100 \%$, isto significa que durante todo o tempo de ciclo, a resistência permaneceu ligada. A Tabela 4 mostra um comparativo percentual de tempo em que a resistência se manteve aquecendo em cada um dos modos de operação.

Tabela 4 - Percentual de tempo comparativo entre modo convencional x arranjo arquitetônico implementado

\begin{tabular}{lc}
\hline Arranjo arquitetônico & $\begin{array}{l}\text { Percentual de tempo em que } \\
\text { se manteve aquecendo (\%) }\end{array}$ \\
\hline Câmera de aquecimento controlador desligado (off) - modo convencional & 75,08 \\
Pré /pós-câmera de aquecimento controlador desligado (off) & 65,50 \\
Pré /pós-câmera de aquecimento controlador ligado (on) & 36,38 \\
\hline
\end{tabular}

Fonte: Próprio autor (2018).

A Tabela 5 mostra os tempos totais de ciclo, a potência consumida por hora de produção, a potência total consumida durante o processo, o preço da energia $(\mathrm{kWh})$, o custo da hora de produção e o custo total gasto para a produção de cinco peças para cada tipo de modo de operação.

Para uma primeira análise da Tabela 5, se faz necessário antes, considerar o valor de $\mathrm{R} \$ 0,44$ pago em cada kWh (unidade) de energia. Assim como também, Energia elétrica total em $\mathrm{kWh}$, e os tempos totais em cada modo operacional, nos quais a resistência permaneceu aquecendo durante o processo de produção, obtendo-se respectivamente as relações de 
consumo por hora de produção de $3,00 \mathrm{kWh}, 2,64 \mathrm{kWh}$ e 1,50 kWh para cada modo operacional.

Tabela 5 - Dados para cálculo da redução do custo de produção, considerando a produção de cinco amostras

\begin{tabular}{lccc}
\hline Parâmetros & $\begin{array}{l}\text { Câmera } \\
\text { controlador } \\
\text { desligado (off) }\end{array}$ & $\begin{array}{l}\text { Pré } \\
\text { controlador } \\
\text { (off) }\end{array}$ & $\begin{array}{c}\text { /pós-câmera Pré /pós-câmera } \\
\text { desligado controlador } \\
\text { ligado (on) }\end{array}$ \\
\hline Tempo de ciclo (h) & 1,52 & 1,33 & 0,78 \\
Energia elétrica kWh /hora & 3,01 & 2,64 & 1,50 \\
Energia elétrica total em kWh & 4,58 & 3,52 & 1,17 \\
$\begin{array}{l}\text { Custo elétrico /hora de produção (unidade) } \\
\text { monetária }\end{array}$ & 1,33 & 1,16 & 0,51 \\
Custo total (unidade) monetária & 2,03 & 1,56 & 0,66 \\
\hline
\end{tabular}

Fonte: Próprio autor (2018).

Adicionalmente a partir da mesma tabela, é possível observar uma redução do custo da hora de produção para cada unidade de $\mathrm{kWh} / \mathrm{h}$ de consumo energético em cada modo operacional, proporcionado pelo percentual de tempo em que houve consumo de energia elétrica durante o período em que a câmera se manteve aquecendo.

Para uma segunda análise, se faz necessário entender como se determina o fator redutor de tempo e do consumo. Para isso, foi comparado percentualmente o valor do consumo de cada hora de produção no modo operacional convencional, à cada um dos modos de pré/póscâmera com o controlador desligado (off) e com controlador ligado (on).

Seguindo a análise, foi possível modelar o fator de redução de tempo e do consumo de energia, que mostra quanto tempo pode ser reduzido para cada unidade de hora de produção, para o incremento de seções com o controlador desligado (off) e com controlador ligado (on). A partir desta modelagem, foi construída a Tabela 6 , em que traz o fator de redução em unidade monetária, no qual o arranjo arquitetônico implementado pode proporcionar.

Tabela 6 - Redução de custo energético /hora de produção em (unidade)

\begin{tabular}{lc}
\hline Arranjo arquitetônico de seções de câmera de aquecimento & Fator de redução (unidade) \\
\hline Pré /pós-câmera controlador desligado (off) & 0,88 \\
Pré /pós-câmera controlador ligado (on) & 0,50 \\
\hline
\end{tabular}

Fonte: Próprio autor (2018).

A análise da redução do custo/hora de produção é feito fundamentado na redução do consumo elétrico do equipamento, onde o valor é apresentado em unidade monetária (BARRETO, 2008; MELO, 2012). 


\section{Conclusão}

Os processos convencionais de produção de rotomoldados possuem longos períodos de ciclo, gerando desperdício energético significativo em cada ciclo produtivo. Diante dos dados obtidos experimentalmente, é possível chegar a um fator redutor, mostrado na Tabela $6 . \mathrm{Na}$ qual pode ser usada por qualquer investidor, como ferramenta de análise para visualizar e quantizar, à redução de custo em percentual que se obtém para cada unidade monetária gasta com energia, em cada ciclo produtivo. Ademais, o arranjo arquitetônico da câmera com controle ligado (on) proporciona resultados mais desejados em comparação à câmera com controle desligado (off), desde que não tenha contratempos no reinício do ciclo seguinte.

A partir dos resultados preliminares deste trabalho podem-se constatar as observações como segue.

- O longo período de ciclo foi minimizado, com o reaproveitamento do calor, da seguinte forma: o pré-câmera reteve o calor na câmara de aquecimento; ao passo que o pós-câmera bloqueou a saída do calor para o meio externo; A cortina térmica existente na entrada do pré-câmera, e na saída do pós-câmera, funciona como porta de acesso e evitou a troca térmica com o meio externo;

- O arranjo tornou o processo menos moroso, face aos outros processos como injeção, termo vácuo e sopro;

- O reaproveitamento energético proposto pode minimizar a queima de gás natural nas plantas existentes.

\section{Referências}

BARRETO, Eduardo José Fagundes (org.). Combustão e gaseificação de biomassa sólida: soluções energéticas para a amazônia. Brasília: Ministério de Minas Energia, 2008. 192p.

GONZÁLEZ-NÚÑEZ, Rubén; MOSCOSO-SÁNCHEZ; Francisco J.; AGUILAR, Jacobo; LÓPEZ-GONZÁLEZ NÚÑEZ, Rosa; ROBLEDO-ORTÍZ, Jorge R.; RODRIGUE, Denis. Thermal analysis of foamed polyethylene rotational molding followed by internal air temperature profiles. Polymer Engineering \& Science, v. 58, n. S1, p. E235-E241, 2018.

MELO, Marcelo Silva de Matos. Energia eólica: aspectos técnicos e econômicos. 2012. 154p. Dissertação (Mestrado em Planejamento Energético) - Universidade Federal do Rio de Janeiro, Rio de Janeiro, 2012.

PISANU, Luciano. Influência do polietileno reciclado nas propriedades de peças obtidas pelo processo de rotomoldagem. 2008. 108p. Dissertação (Mestrado em Ciência e 
Engenharia de Materiais) - Universidade Federal de Campina Grande, Campina Grande, 2008.

REVYAKO, M. M.; KHROL, Eugene. Z. Certain Problems of Heat and Mass Transfer in Rotational Molding. Journal of Engineering Physics and Thermophysics, v. 83, n. 5, p. 1089-92, 2010.

REVISTA Ferramental, ano III, n. 13, jul./ago. 2007.

RUBIO, Eduardo. Innovative Wireless Technologies for Real-Time Rotational Molding Processes Optimiztion. IEEE Latin America Transactions, v. 14, n. 1, p. 78-82, 2016.

SLĂTINEANU, Laurenţiu; DODUN, Oana; COTEAȚĂ, Margareta; GONÇALVESCOELHO, António; BEŞLIU, Irina; GHERMAN, Lorelei; POIENARU, Maricela. A Preliminary Study on the Rotational Molding Process. Proceedings in Manufacturing Systems, v. 7, n. 1, p. 25-30, 2012. 